\title{
LOS DOMINIOS VALENCIANOS DE LA CASA DE MEDINACELI ENTRE LOS SIGLOS XVI Y XVIII. EL DUCADO DE SEGORBE *
}

por

\section{ANTONI F, GRAU ESCRIHUELA}

Universidad de Valencia.

RESUMEN: En los señorios valencianos de la Casa de Medinaceli, la expulsión de los moniscas tuvo efectos negativos, pero no catastróficos. La repoblación impulsó el proceso de concentración de la propiedad de la tierra y supuso una reorganiqación del régimen señorial que le permitió adecuarse mejor a los movimientos inflacionistas. Los establecimientos enfitéuticos de los bienes que pertenecieron a los moriscos originaron unas comunidades rurales bastantes bomogéneas, aunque paulatinamente se incrementó su diferenciación interna. Hasta mediados del siglo XVIII seguian constituyendo ejemplos tipicos de sociedades agrarias con un escaso grado de movilidad social.

PALABRAS CLAVE: España. Valencia. Historia social y económica, siglos XVI-XVIII.

ABSTRACT: In the Valencian Seigniories of the House of Medinaceli, the expulsion of the Moorish bad its negative effects, but not catastropbic. The repopulation impelled the concentration process of the property of the land and supposed a reorganization of the lordly regime that permitted be adapted better to the inflationary movements. The empbiteutic establisbments of the properties that belongs to the Moorish originated rural communities quite bomogeneous, thought gradually their internal differentiation was increased. Until the middle of XVIIIth century they were constituting typical examples of agrarian societies with a scarce degree of social mobility.

KEY WORDS: Spain. Social and economic history from the XVIth century to the XVIIIth century.

\footnotetext{
* Este trabajo recoge el cuerpo central de la tesis Señorio y propiedad en el Pat́s Valentiano. Los dominios de la Casa Ducal de Medinaceli, defendida en Valencia en noviembre de 1993.
}

Hispantic, LVIII/3, nưm 200 (1998) 995-1019 
Con este trabajo se pretende contribuir al conocimiento de los dominios señoriales valencianos de la Casa Ducal de Medinaceli, en concreto, del ducado de Segorbe -y, para algunos aspectos, del marquesado de Dénia- desde la expulsión morisca hasta mediados del siglo XVIII. El estudio abarca, en primer lugar, el marco socio-económico, jurídico e institucional determinado por las cartas-puebla otorgadas a raíz del extrañamiento criptomusulmán, Posteriormente, se analiza la evolución de la estructura del dominio útil originada por los establecimientos enfitéuticos de los antiguos bienes moriscos a los nuevos repobladores. Y, para finalizar, se comprueba la composición y dinámica de la renta ducal. Respecto de los dos últimos apartados propuestos (estructura del dominio útil y evolución de la renta), el ámbito de estudio se ciñe al ducado de Segorbe, reuniéndose las baronías que lo integraban en tres grandes unidades: las poblaciones de la Sierra de Eslida; Segorbe y Geldo; y la Vall d'Uixó. Las razones de este agrupamiento radican tanto en su proximidad y afinidades topoecológicas como en la propia inercia señorial de considerarlos como un todo. Los análisis globales que se efectuarán a partir de los cabreves de cada uno de dichos grupos permitirán salvar las limitaciones de los estudios de escala local.

En definitiva, se intenta demostrar que la expulsión de los moriscos supuso, para la mayoría de los dominios valencianos de la Casa de Medinaceli, una notable reestructuración del régimen señorial. Pero también que dicha reorganización, que no llevaba implicito un proceso de refeudalización, tuvo su concreción más palpable en el reparto de los bienes que habían pertenecido a los moriscos mediante el sistema de establecimientos enfitéuticos. $\mathrm{Y}$, finalmente, que la evolución de la renta señorial confirma que las consecuencias de la expulsión no fueron, ni mucho menos, catastróficas en los casos estudiados.

\section{FUENTES DOCUMENTAIES}

Si en líneas generales, las cartas-puebla permitirán enmarcar social, jurídica, política y económicamente el estudio a lo largo de todo el período, dada la importancia de la enfiteusis en los señoríos valencianos de la Casa de Medinaceli, los cabrever serán otro referente fundamental en la investigación. Como es sabido, se trata de una documentación valiosísima cuyas posibilidades para el análisis de la estructura agraria son múltiples, desde la parcelación y morfología de los cultivos a los ingresos señoriales provenientes del dominio directo. $\mathrm{El}$ interés señorial por la cabrevación respondía a los objetivos de controlar el dominio útil (actualizando las transformaciones habidas), percibir las rentas que por él se habian estipulado en las capitulaciones y reafirmar sus derechos ante un notario, que daba validez jurídica a los reconocimientos. Estudiando la estructura y evolución del dominio útil y su reparto social se podrá saber a favor de quién se operaban las concentraciones de tierras, así como el peso específico de la economía campesina. Sociológicamente, además, podrá acotarse la movilidad del factor tierra a partir del estudio de aspectos como la in-

Hispania, LVIII/3, núr. 200 (1998) 995-1019 
versión en tierras de la llamada burguesía agraria o el proceso de pauperización. Pero aparte de aportar información exhaustiva sobre la situación estructural o sincrónica de la propiedad agraria, estas fuentes permiten rastrear su evolución. Como se trabaja con series completas de cabreves, será factible contrastar los reconocimientos enfitéuticos de un mismo lugar en diferentes épocas y de diversos lugares en fechas próximas o distantes. Aún así, hay aspectos que escapan a las posibilidades de esta documentación, «(...) qui cultiva la terra (el mateix propietari o parcers $i$ arrendataris), la producció, els preus $i$ la importància de la ramaderia i, per l'estudi de la societat rural, la figura del pagés comerciant, introductor del capitalisme en la societat agrària tradicionaly'. Pero precisamente por cuanto se es consciente de los límites que entraña la utilización de los cabreves, pueden considerarse como una fuente de consulta ineludible para el estudio de la estructura de la propiedad en tierras de señorío laico y con la enfiteusis como figura absolutamente predominante.

\section{LAS CARTAS DE REPOBLACIÓN POSTERIORES A LA EXPULSIÓN}

El estudio de las capitulaciones se ha revelado como un elemento clave para la comprensión de la historia del País Valenciano ${ }^{2}$. Cierto es que a algunos de los señorios valencianos que convergerían en la Casa Ducal no se les otorgaron cartas-puebla por no contar con pobladores moriscos en 1609, bien sea porque no los tuvieron nunca (casos de La Pobla de Vallbona, Dénia o Xàbia), bien porque pobladores cristianos viejos los habían ido sustituyendo (Paterna, Palma, Ador y Callosa d'En Sarrià). No obstante, la zona que nos ocupa en este estudio era marcadamente morisca; tanto es así que, antes de la expulsión, la población de la Sierra de Eslida era musulmana en su totalidad ${ }^{3}$. La tepoblación del arrabal de Segorbe implicó una problemática diferente. Por encontrarse entonces bajo secuestro real, los establecimientos no los realizaton los agentes ducales, sino funcionarios de la Corona. En junio de 1612 se mandó hacer un inventario de todos los bienes que dejaron los moriscos de dicho arrabal; poco después, don Salvador Fontanet, comisario real, efectuó la petición para su repoblación, de modo que se establecerían en nombre de su Majestad y «(...) en favor de las personas que pareixeran totes y qualsevols cases y terres, axi de orta com de secà, que los moriscos expellits del dit raval de Segorb en lo temps de la

1 Feluu i Monfort, G. (1978), pág. 215.

2 Véanse, entre otros, Gil OlCiNA, A. (1979), Guinot, E. (1986) o Pla alberola, P. (1986). Para CISCAR, E. (1977), pág. 169, «Las cartas-puebla son un documento indispensable para el conocimiento del régimen señorial establecido uex novo» a principios del siglo XVII y que se mantendria, en lineas generales, hasta la crisis del Antigno Régiments.

3 BUTZER, K.W. y otros (1986), pág. 342. Las cartas del ducado de Segorbe se encuentran en el Archivo de la Fundación Casa Ducal de Medinaceli, en Sevilla (en adelante, A.D.M.), Sección Segorbe (leg. $6, n^{\circ} 1,2-c, 4,6,7,34$; leg. 8, $n^{\circ} 14$; leg. 10, $n^{\circ} 13$ i 15). La de el Verger, en el Archivo de la casa Ducal de Lerma, en Toledo (A.D.L.), legajo $16, \mathrm{n}^{\circ} 22$.

Hiqqania, LVIII/3, núm. 200 (1998) 995-1019 
expulsió possebïen, axi en dit raval com en la matexa ciutat de Segorb y en lo terme de aquella) ${ }^{4}$.

La localización de las poblaciones a las que se concedieron las cartas-puebla abarca las tres provincias valencianas, con una diversidad espacial que va desde las comarcas interiores (el ducado de Segorbe, con la Vall d'Uixó, Fondeguilla, Castro, Aín, Alcudia de Veo, Veo, Eslida, Fanzara, Suera y Geldo) a las litorales (el Verger), pasando por las centrales (Benaguasil, del «Antiguo Patrimonio» del duque de Segorbe). En consecuencia, el presente estudio permite un análisis comparativo de las capitulaciones de lugares de un mismo estado señorial pero situados geográficamente en zonas muy diferenciadas.

Fig. $\mathrm{n}^{\mathrm{a}}$ 1. Localización geográfica de los lugares incluidos en las cartas-puebla estudiadas

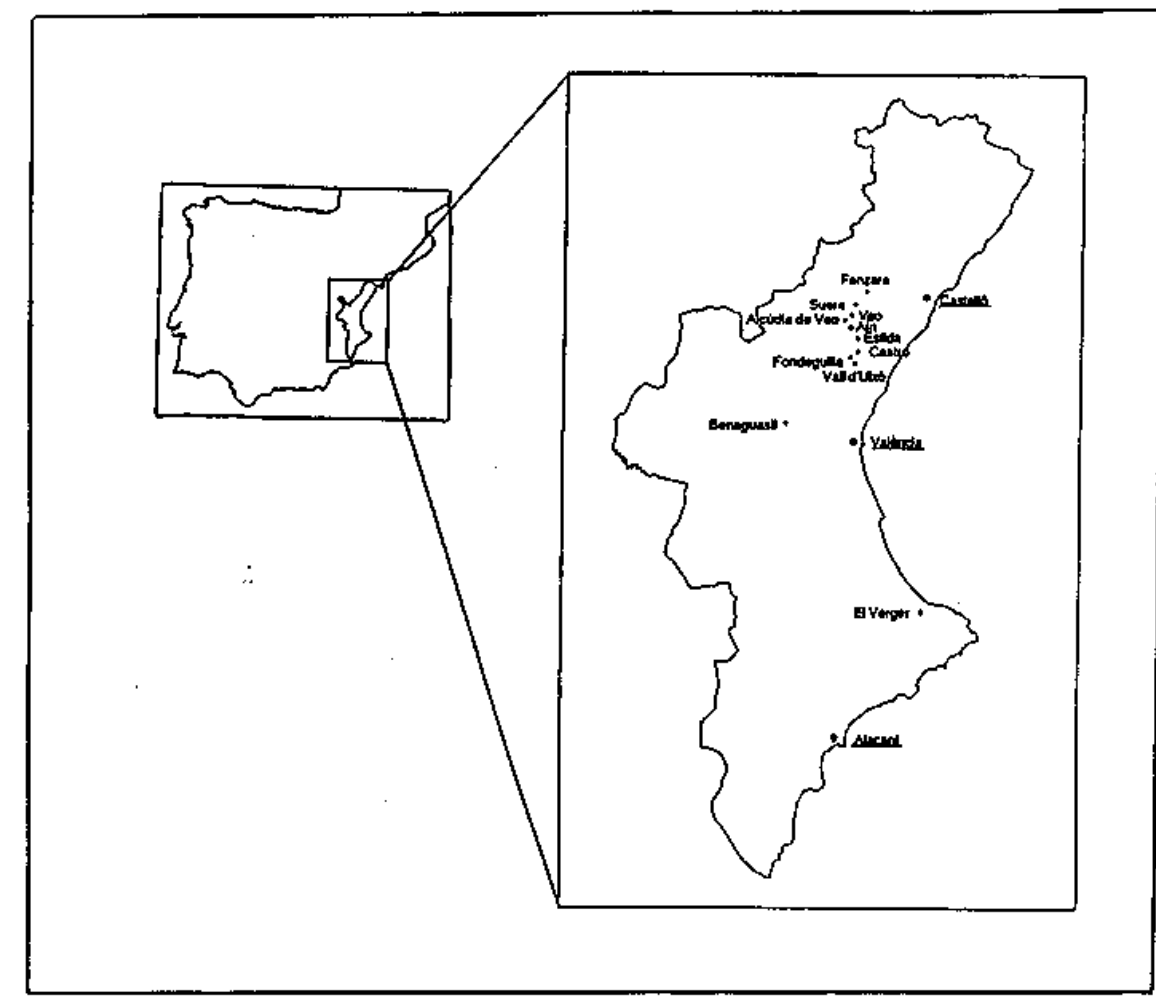

4 Archivo del Reino de Valencia (A.R.V.), Manaments i Empares, año 1621; libro 7, mano 64 , ff. 24 y 25 .

Hispania, LVIHI/3, núm. 200 (1998) 995-1019 
Respecto de la cronología de su concesión, hay una clara diferencia entre el Verger, entonces del duque de Lerma, que se otorgó en 1610; y el resto de baronías, del duque de Segorbe, concertadas mayoritariamente en 1612. Para el profesor Reglá, «(...) en el Sur del reino, la repoblación se caracterizó por una fuevte reatción señorial (...) ello se debería a una mayor oferta de repobladoress ${ }^{5}$. Sin embatgo, no es suficiente quedarse con la oferta de pobladores como único factor que explique su cronología, ni tampoco con otro tan importante como el de «(...) disipar el miedo del embargo por parte de los censalistas" ". Un buen ejemplo lo constituiría el doble pleito que mantuvo el duque de Segorbe, por una parte con la ciudad de Valencia por la jurisdicción del «Antiguo Patrimonio» (necesaria para la repoblación de Benaguasil); y por otra, a causa del dominio útil upropi de las iglesias, olim mesquitas, $y$ dels pobres, agregats a ditas iglesias» también de Benaguasil, con su administrador general. El duque conseguirá imponerse en el primer pleito que se temonta al empeño de las rentas y la jurisdicción de Paterna, Benaguasil y La Pobla de Vallbona realizado por el rey Alfonso de Aragón en 1430 por un empréstito de 75000 florines--; pero no ganará el otro proceso: la sentencia de 1614 le fue desfavorable?

Mención aparte merece el «caso Villalta», responsable de la dilación temporal de las capitulaciones de repoblación y los establecimientos enfitéuticos. La cuestión se podría tesumir así: Antonio Villaita, contador general del duque de Segorbe en los estados de Cataluña, recibió de éste el encargo de otorgar las nuevas cartas-puebla en sus dominios valencianos; pero siendo un hombre ambicioso, sólo vio en elio un negocio y la posibilidad de entiquecerse. Arbitrariamente, sin hacer establecimientos, dio tierras y extorsionó a los pobladores, hasta el punto que intervinieron el regente y el duque, el cual debió enviar nuevos agentes para llevar a cabo su cometido ${ }^{8}$. Otra cuestión es que la autoridad ducal pudiera recompensar o no la labor de quienes contribuyeron a que la repoblación se resolviera favorablemente. De hecho, en la Vall d'Uixó, determinados representantes señoriales se quedaron con cuantiosas propiedades de los moriscos expulsos?.

En el estudio del reparto del dominio útil, un factor básico lo constituye el hecho de que, en todas las poblaciones, fue la figura de la enfiteusis la que posibilitó los establecimientos de tierras y casas a los nuevos pobladores. Sin embargo, no sería tanto que el señor optara por dicho método, como que quizás no pudo imponer derechos de propiedad absoluta sobre sus posesiones - que le hubieran permitido introducir el arrendamiento a corto plazo- y tuvo que conformatse con el control de sus regalías y reducidas propiedades plenas. El sistema de arrendamiento a corto plazo parecía «(...) inviable, si no impensable, ante el caos agrario, ante unos re-

\footnotetext{
5 REGL $\lambda$, J. (1971), pág. 168.

6 CISCAR, E. (1977), pág. 175.

7 A.D.M., Sección Segorbe, legajo 79, números 386, 390 y 391.

B PeñARrojA L. (1984), págs. 325-353 y 776-831.

- Atchivo de la Casa Ducal de Medinaceli (en adelante, A.D.M.), Sección Segorbe, legajo $79, \mathrm{n}^{\circ}$ 444-446 («Memorialy raçón de les terres que tenen repartides»).
}

Hiphania, LVIII/3, núm. 200 (1998) 995-1019 
pobladores escasos e inestables, propensos a acudir a lugares donde ofreciesen mejores condiciones y deseosos de convertirse en propietarios. La enfiteusis parece ser la solución equilibraday ajustada a las circunstancias, pues al conceder el dominio util de la tierra, se permite por un lado el acceso a la propiedad del campesino y por otro se te vincula en principio al lugar como poblador, babitante y cultivador, objetivo perseguido por la nobleza ${ }^{10}$.

En general, a cada repoblador se le debía adjudicar como mínimo una casa, pero nunca se especificaba la cantidad de tierra de cultivo a repartir. Eso sí, es de suponer que se distribuirían todas las del término. Así lo sugieren tanto inexistencia en la práctica de la reserva señorial como la información de testigos acerca de los menoscabos sufridos por el duque de Segorbe desde la expulsión hasta los establecimientos de 1612-13 ${ }^{11}$.

Las condiciones fijadas para la adquisición, conservación y transmisión del dominio útil perseguian el objetivo de asegurar la mejor explotación económica de cada lugar. Evitar que los enfiteutas abandonasen el señorio, una vez establecidos los correspondientes bienes, será la principal medida a tomar. Por ello, en todas las cartas figura una constante: la amenaza del comiso. La confiscación de tierras y casas era el castigo para quienes se fuesen antes de los cuatro primeros años de residencia, pero también para los que se ausentaran del señorío por un tiempo que oscilaba entre los dos y seis meses. En cuanto a la transmisión del dominio útil, además de la licencia señorial y el derecho de fadiga, el comprador (que no podía ser ni una persona privilegiada ni exenta, sino alguien que cumpliera todas las condiciones pactadas) se había de avasallar y residir personalmente con su familia. Además, no admitiría a quienes anteriormente hubieran sido beneficiarios de establecimientos en otros lugares tras la expulsión. En un momento en que la repoblación era una necesidad urgente, esta medida iría encaminada a reforzar la estabilidad de la ocupación del terrazgo y a disuadir a los campesinos más disconformes que buscaban mejores ofertas.

Una cuestión básica era saber quién habría de afrontar los censales moriscos (para calibrar su importancia baste citar que, antes de la expulsión, los ingresos del ducado de Segorbe servían únicamente para hacer frente al pago de estas deudas). Pues bien, fue el noble titular quien las asumió, con la excepción de el Verger. Allí, el señor prometió ayudar a los recién llegados con 100 libras en 1610 y con otras 150 los tres años siguientes; con todo, dicha solución —que podría estar relacionada con que su titular fuese D. Francisco Gómez de Sandoval y Rojas, duque de Lerma y $V$ marqués de Dénia, a la sazón valido de Felipe III ${ }^{12}$-, era más desfavorable para los repobladores que la adoptada en el resto de poblaciones. La ciudad de Segorbe no constituyó una excepción a la práctica general y «Por la señoría directa del expolio de Segorbe paga cada un año su Ex-

10 CISCAR, E. (1993), pág. 191.

11 A.D.M. Sección Segorbe, legajo 62.

12 Mucho es lo que se ha escrito acerca decisiva intervención del duque de Lerma y sus intereses en la expulsión. CÍSCAR, E. (1993), ppág.193-196, perfila una breve síntesis historiográfica.

Hispania, LVHI/3, núm. 200 (1998) 995-1019 
celencia las pensiones de los censales (...) a diferentes iglesias, cofradias, beneficios y otros particulares, por estar cargados sobre los bienes de la aljama y moros expulsoss ${ }^{13}$.

El objetivo de asegurar la alimentación de los vasallos se materializó en una protección de los cereales. $Y$, de manera complementaria, se estimuló la plantación de determinados árboles (viña, algarrobos e higueras) ofreciendo una exención temporal (de ocho a diez años) de la partición de frutos. En cuanto a las regalías o derechos prohibitivos y exclusivos, tanto las ya existentes como las que se construyeran en un futuro serían propiedad del señor, el cual las explotaría en beneficio propio. La Casa Ducal estaba, lógicamente, muy interesada en asegurarse su utilización por cuanto abarcaban las principales actividades del mundo rural (moler el grano, cocer el pan, etc.) y representaban una fuente de ingresos clave. Al mismo tiempo, reforzaba la inmovilidad del sistema al trabar cualquier intento de comercialización que sobrepasase unos máximos para cada producto. En todas las cartas figuraban las siguientes regalías: molino, horno, fleca o panadería, carnicería, almácera, taberna y minas que hubiera. Pero también había otras, como hostal y fonda (Benaguasil, Fanzara, Castro y Fondeguilla), molinos arroceros, dehesas, hierbas y pastos (Benaguasil) o las montañas como tales (Fanzara, Suera). Las penas por no utilizarlas eran bastante elevadas. Además, el que se repartiera la multa entre las tres partes implicadas (el duque, el arrendatario de la regalia en cuestión y el acusador) podía constituir un sistema de incitación a la denuncia entre los propios enfiteutas - sobre todo en coyunturas difíciles- y, por tanto, de potenciar el resquebrajamiento de las relaciones de solidaridad interna de la comunidad campesina.

Respecto del gobierno y administración del señorio, la mejor forma que tenía el noble titular de maximizar los beneficios que le reportaba - asegurándose el cobro de las rentas y el cumplimiento de las normas establecidas-, era, por su absentismo, confiarlo a un hombre de confianza: el baile o alcaide $o$, en un escalafón superior, el procurador general. En consecuencia, serían los agentes ducales los encargados de controlar aspectos fundamentales como la partición de frutos, la transmisión del dominio útil, las licencias para determinados cultivos, perpetuar la función exclusivista de los monopolios, etc.

Por constituir la base sobre la cual descansaba la organización jurídica y económica del régimen señorial, el vasallaje era un requisito esencial de cualquier establecimiento. Los repobladores habian de jurar fidelidad al señor, reconocerle como poseedor directo de todos los bienes y aceptar su jurisdicción. Aparte de la mediatización en la elección de los representantes de los vecinos (entre los cuales destacaban los cargos de justicia, jurados y mostasá), el poder jurisdiccional del señor llegaba a prohibir reunir el Consell General sin la correspondiente licencia, así como a imponer ordenaciones (variables según su voluntad) para el buen gobierno del señorío. En suma, la administración de justicia, privatizada y umbilicalmente unida al control señorial sobre los vasallos,

13 A.D.M. Sección Archivo Histórico, legajo $57, \mathrm{n}^{\circ} 64$.

Hipanaia, LVIII/3, nús. 200 (1998) 995-1019 
se basaba en la absoluta autoridad del señor que le confería la posesión de la jurisdicción civil y criminal, alta y baja, mero y mixto imperio. De exclusiva competencia suya era nombrar los jueces competentes o designar el notario encargado de recibir «totes les vendes, alienacions y transportacions e regoneixenses, e altres qualsevols gèneros de actes que faran de dites cases e terres».

En cuanto a los censos enfitéuticos, contribuciones en metálico y particiones de frutos constituían fuentes fundamentales de los ingresos señoriales. Para las casas, sólo las de el Verger y Benaguasil respondían a un canon anual fijo (de 10 y 25 sueldos, respectivamente). En los demás lugares, el censo era proporcional al valor del bien establecido: oscilaba entre los seis dineros por libra de la tercera parte de la valía total de las casas (Sierra de Eslida, Fanzara, Suera y Castro y Fondeguilla) y los seis dineros por libra pero de la mitad de aquel valor (Geldo). Para la tierra se observa una mayor complejidad. Puede establecerse, en principio, una diferenciación entre las cartas otorgadas por el duque de Segorbe y la de el Verger, donde los censos eran uniformes para el regadio y el secano (con una prestación única de seis dineros por cahizada, esto es, media hectárea). En el ducado de Segorbe, la carga más elevada de regadío era la de Geldo, con tres sueldos por hanegada, seguida por los dos sueldos de la Vall d'Uixó; la más frecuente, seis sueldos por cahizada (Suera, Fanzara, Benaguasil); la menor, cuatro sueldos (Sierra de Eslida, Castro y Fondeguilla). Para la misma unidad de superficie, en el secano oscilaba entre los seis dineros de Benaguasil y los dos sueldos de Fanzara, Geldo y Suera. En conjunto, estas prestaciones se pueden considerar como suaves $y$, por la devaluación a la que se verían sometidas con los años, de menor importancia que las particiones de frutos, núcleo fundamental de los ingresos señoriales. Dado que cereales, hortalizas y legumbres suponían la dieta básica de la comunidad rural, su partición se erigía en la más representativa. El hecho de encontrarlos en tierras de secano o de regadía no siempre hacía variar la parte alícuota exigida. Excepto en el Verger, donde los enfiteutas se obligaron a dar la cuarta parte de lo recogido, las particiones tampoco eran demasiado onerosas, situándose entre $1 / 6$ y $1 / 8$ en la huerta, y entre $1 / 6$ y $1 / 10$ en el secano. Las particiones de los árboles (viña, algarrobos, higueras, moreras, olivos, almendros o alcornoques) eran similares a las anteriores.

Por lo que respecta a la identidad de los nuevos pobladores, para los lugares donde se dispone información, el predominio de labradores era manifiesto: representaban la totalidad de los nuevos repobladores en el Verger, el $75 \%$ en Benaguasil y $88 \%$ en Geldo. Aún así, no faltaron representantes de oficios propios de los núcleos urbanos. Pese a no especificarse su cualificación, no sería lógico que se tratase de individuos con una sólida posición social y económica, así como que, tanto trabajadores mecánicos como labradores no propietarios, intentaran convertirse en repobladores poseedores del dominio útil, huyendo de una situación insegura y de una marginación evidente. Por su procedencia geográfica, la mayoría de los recién llegados provenian de zonas cercanas al lugar a repoblar, lo cual explica que la repoblación se llevara a término fundamentalmente con efectivos valen-

Hiqpamia, LVIII/3, núm. 200 (1998) 995-1019 
cianos: en Geldo representaban el 81\% del total, en Benaguasil el $87 \%$ en 1613 y en El Verger todos eran de Xàbia y Dénia.

Por lo que se refiere a los servicios personales, los repobladores tenían la obligación de conservar la infraestructura del riego y de mantener murallas, portales y cárceles. Dada la escasa magnitud de la reserva señorial (sólo en la Vall d'Uixó hay una referencia al «jardin y buerto de su Excelencia»), las prestaciones personales eran prácticamente inexistentes. Como mucho, en el Verger se fijaba un turno de trabajos obligatorios, pero retribuidos. Algunas poblaciones debían satisfacer el derecho de «alcaydiat»: en Benaguasil, consistía en una arroba de algarrobas, un «almut de tot gra $i$ llegums» y un cuartón de lino y cáñamo por cada casa; en Suera y Fanzara, en un «almub» de harina de maíz y otro de panizo. General y uniforme era el derecho de "morabatis, que suponia en todos los lugares en un sueldo por casa. Por último, en el Verger se exigia un presente navideño para el señor, regalo colectivo de todos los habitantes que debía ser equivalente a cuarenta reales castellanos; pero esta prestación es significativa, justamente, por su excepcionalidad.

Un aspecto novedoso, por cuanto indica que el régimen señorial no fue una realidad inmutable en el tiempo, es el referido a las concordias concedidas por el titular del señorío para modificar las condiciones de las cartas-pueblas. Pasamos así a ocuparnos de la vigencia y modificaciones de las cartas-puebla. Las concordias aquí analizadas estipulaban mejoras para los campesinos respecto del puntal económico del régimen señorial: las particiones de frutos. Estas quedaron reducidas en el regadio a la octava parte en la Vall d'Uixó (1658) y a la novena en Benaguasil (1649 y 1659) y Paterna (1640) ${ }^{14}$. Atendiendo a la cronología señalada, su concesión no vendría determinada por exigencias de la repoblación o por cuestiones coyunturales como las climáticas, aducidas por los representantes municipales de Paterna en pleno proceso repoblador; más convincente es inclinarse por la capacidad del campesinado de fotzarlas. En este sentido, un buen punto de referencia es el geográfico, ya que la mayoría de las modificaciones se dieron en lugares de mayor riqueza agrícola. Parece evidente, pues, que la presión señorial encontrará cada vez más oposición e irá disminuyendo en un momento clave para la historia del País Valenciano.

Puede intentarse, por último, un balance comparativo de las cartas-puebla con la situación que las precedió. No se intenta aquí realizar una revisión historiográfica a propósito del tan debatido tema de la refeudalización, ni referir las contradictorias e interesadas tomas de posición contemporáneas a la expulsión. Lo que se propone es determinar el proceso de gestación de las cartas fundacionales allí donde se tiene constancia documental, así como efectuar un estudio comparativo con la situación anterior de cada señorío. Es cierto que después de la expulsión, con la política pro-nobiliaria de la monarquía frente a los censalistas, la casa ducal mejorará su endeudamiento, disponiendo de unas

14 A.D.M. Sección Segorbe, legajo 6, $\mathrm{n}^{\circ} 6$ y $\mathrm{n}^{\circ} 7$.

Hispania, LVIII/3, núm. 200 (1998) 995-1019 
rentas que, hasta entonces, había tenido que hipotecar. Con las cartas-puebla otorgadas, base del nuevo régimen señorial, se racionalizó la percepción de las rentas, convirtiendo las particiones y los censos en metálico en las fuentes fundamental y complementaria, respectivamente, de sus ingresos; con ellas era posible afrontar los procesos inflacionarios, sin olvidar los derechos monopolísticos y el tercio-diezmo, que ofrecerían crecientes ingresos. Sin embargo, no puede decirse que el señor impusiera unas cargas más onerosas para sus nuevos vasallos que las que habían soportado sus antecesores moriscos. Además de las diversas ordenanzas y pragmáticas reales consultadas ${ }^{15}$, ni la parte alícuota a abonar se puede incluir entre las más duras del País Valenciano, ni eran demasiado elevados los censos en dinero, ni tampoco de excesiva consideración la mayoría de las demás obligaciones a las que quedaban sometidos los vasallos. Todo lo cual no significa, de ninguna manera, que las exacciones feudales no se dejaran sentir en una economía atrasada y de subsistencia.

En los dominios del antiguo alcadiazgo de Eslida y el conjunto formado por la Vall d'Uixó, Castro y Fondeguilla, el incremento neto que experimentó la renta ducal después de 1609 , no debe entendetse como resultado de una intensificación de la coacción feudal, sino como la respuesta a la racionalización de las exigencias. Aparte de que las exacciones tributarias se habían incrementado por aportaciones irregulares y extraordinarias, y del creciente esfuerzo a que se vio sometida la población morisca especialmente desde 1530 , pueden aludirse otras razones que confirman este planteamiento. Que las cartas-puebla constituyen en sí mismas la referencia legal de las nuevas relaciones feudales; referencia legal que en un futuro blandieron en diversas ocasiones los vecinos ante determinadas pretensiones señoriales ${ }^{16}$. Y es que con una fiscalidad menos regulada, tenía cabida un mayor grado de arbitrariedad señorial. Pero además, y en relación con las disponibilidades pecuniarias, J. Casey apunta que la generalización de los pagos en especie «(...) no era potser enterament una reació per part dels senyors a la devaluació dels antics censos deguda a l'aguda inflació del preus del segle XVI. La parceria semblava tenir sentit quan hi bavia camperols pobres que arribaven als repoblaments sense recursoss ${ }^{17}$. La oposición de los repobladores a los capítulos propuestos por los agentes ducales incidía en dicha dirección. Otros aspectos que abundarían en el mismo planteamiento serían que los nuevos pobladores no tuvieron que afrontar las deudas por censales de las aljamas o cargados sobre ellas; ni estuvieron obligados a realizar servicios personales a la señoria; ni debieron pagar el diezmo en especie, sino ajustado en una cantidad fija ( $y$, por tanto, devaluable) en dinero,...

En Benaguasil i el Verger, la comparación con la fiscalidad anterior a la expulsión es más sencilla por ser directamente contrastables los elementos que la

15 Por ejemplo, el pregón del marqués de Catazena de 15 de diciembre de 1609 limitaba las particiones de frutos a la quinta parte, «Y si de diter terres se fya responsio menor del quint, com és a la sisena, séptima o de abi avant, que sols ajen de respondre alló que acostumaven) (BORONAT, P. (1901), págs. 567-568).

16 Véase PESET, M.(1987), págs. 203-239.

Hispania, LVIII/3, nún 200 (1998) 995-1019 
componían (los moriscos habían de entregar también particiones alícuotas de la cosecha, censos en dinero, etc.). Los arrendamientos de los derechos dominicales de Benaguasil y la Pobla de Vallbona de 1540-1543 y 1605-1607 is refieren una retahila de derechos feudales de los cuales no se realizaba ninguna mención en la carta-puebla de 1613; así mismo, el censo monetario era de 4 sueldos y 6 dineros por tahúllia de huerta y, respecto de la partición de frutos, parece más onerosa la cuantía anterior a la expulsión (sirvan como ejemplo la de cereales, hortalizas y legumbres, por los que se pagaba en la huerta la quinta parte y en el secano la octava).

Para referirnos a la situación posterior a la expulsión, debemos resaltar la necesidad que tuvieron los representantes señoriales de realizar, al menos, un triple esfuerzo en la negociación con los nuevos pobladores de Benaguasil para la configuración de la carta-puebla. Es evidente que fueron los enfiteutas quienes forzaron la concesión por parte del duque de la contribución que consideraban menos perjudicial: la partición de frutos. Muchos se fueron, abandonando casa y tierras, tras conocer las fuertes cargas monetarias fijadas en 1611; frente a los 132 nuevos pobladores que identificaba la escritura de dicho año, la de 1613 sólo contabilizaba 76. Aunque un elevado porcentaje de ellos figura en ambos documentos, la pérdida de un $42 \%$ del total no puede menospreciarse. Pero no sólo eso. Como ponen de manifiesto las respuestas de los nuevos pobladores a otros borradores de cartas-puebla propuestos por la autoridad ducal, tampoco se conformaron con las particiones que anteriormente habían soportado los pobladores moriscos ${ }^{19}$. Aunque no todas sus peticiones quedaron reflejadas en la carta de 1613 , no hay duda de una dinámica negociadora. Por lo tanto, se puede concluir que las capitulaciones no pueden ser definidas aquí como una mera imposición señorial. En el proceso también se habría de contar con otros factores que quizás influyeran en la actitud del duque (sucesión de dos años de malas cosechas, la actuación de Antonio de Villalta,....), pero se debe resaltar el mérito de los repobladores por saber aprovechar la coyuntura.

Para finalizar, la capitulación de l Verger constituí, comparativamente con el resto de las cartas analizadas, el caso de mayor dureza de las condiciones señoriales. Sin embargo, contrastando las exigencias de 1610 con las que satisfacían los moriscos ${ }^{20}$, tampoco hubo un incremento de la presión feudal. Y es que, de acuerdo con la citada fuente, los campesinos moriscos debían abonar al señor un censo de 21 ó 22 sueldos por cada casa, una partición de frutos que oscilaba entre la mitad de la cosecha de los árboles y el tercio de la de los granos, pagar el tercio-diezmo de totes les beretats, entregar un presente en Navidad

17 CASEY, J. (1981), pág. 130.

18 A.D.M., Sección Segorbe, legajos 79, $\mathrm{n}^{\circ} 108$ y 58, $\mathrm{n}^{\circ} 19$. A.R.V. Batlia, Apéndice $\mathrm{n}^{\circ} 61$, f. $315 \mathrm{r}^{\circ}$ y $v^{\circ}$.

19 A.D.M., Sección Segorbe, legajo $79, \mathrm{n}^{\circ} 451, \mathrm{c} . \mathrm{X}$. A.B.II.2)

20 Se detallan en su cabreve de 1596 (A.D.M., Sección Libros y Manuscritos, Signatura 
(consistente en seis gallinas, una arroba de miel, dos arrobas de pasas y seis docenas de palmitos), hacerle trabajos diversos, etc.

Efectuado el balance comparativo, desde una óptica demográfica, interesa comprobar la continuidad personal de los repobladores. Para ello, se han cotejado los apellidos de los que firmaron las cartas-puebla con los de los enfiteutas de los cabreves de mediados del siglo XVII. El resultado es que aparecían muchos de ellos, pero no todos, junto a otros nuevos, a quienes fue necesario establecer enfitéuticamente casas y tierras. Del contraste efectuado se desprende también que, pese a no alcanzarse ni de lejos los efectivos anteriores a la expulsión, la tendencia hacia la estabilidad demográfica es, en conjunto, positiva. En todo caso, la fertilidad de la tierra y las cargas feudales a soportar marcaron notorias diferencias de unas zonas a otras. Con una repoblación selectiva, no es de extrañar que Benaguasil se convirtiera en un foco privilegiado de atracción de enfiteutas.

\section{REPARTO, USOS Y EVOLUCIÓN DEL DOMINIO ÚTIL, 1613-1740}

En este apartado se hará hincapié en los resultados estadísticos para establecer comparaciones sincrónicas y/o diacrónicas, de las cuales partirán las conclusiones sobre el reparto y caracterización evolutiva del dominio útil en cada lugar desde 1613 a 174021 .

La complejidad del régimen de la propiedad en Segorbe (junto a bienes enfitéuticos, se incluían otros francos o alodiales) obliga a otorgar a esta ciudad un tratamiento diferenciado. El cabreve practicado entre 1550 y 1573 refería un dominio útil constituido esencialmente por inmuebles urbanos; los predios rústicos aparecían, además, con una imprecisa expresión de su superficie. Los moriscos representaban entre un $40 \%$ y un $52 \%$ del total de enfiteutas, aunque el valor de su patrimonio alcanzaba niveles más modestos. Pese a las omisiones respecto del estatus socio-profesional de los censatarios, debe resaltarse, entre los cristianos viejos, una notable presencia de capas urbanas. Por lo que se refiere a las formas de acceso al dominio útil, Segorbe se definía ya en el siglo XVI como un mercado abierto (las compra-ventas de tierras igualaban a herencias y donaciones matrimoniales tomadas conjuntamente). En el caso de las transmisiones intrafamiliares moriscas, la información sugiere que los bienes heredados eran "transportados» (vendidos o donados sin especificarse más) a un descendiente varón, mecanismo susceptible de atenuar los efectos de la división por herencia en partes iguales.

21 Los cabreves consultados se encuentran en el A.D.M, Sección Segorbe. Los de Segorbe, en los legajos $49\left(n^{\circ}\right.$ 5), 51 (n $\left.{ }^{\circ} 1\right)$ y en la Sección Libros y Manuscritos, A.H.III.18. Para las restantes baronias, todos en la Sección Segorbe: los establecimientos de 1613 en el legajo 73; los de 1651 en los legajos $52\left(n^{\circ} 1\right)$ y $53\left(n^{\circ} 3\right)$; los de 1729-1740 en los legajos $51\left(n^{\circ} 2,12\right), 52\left(n^{\circ}\right.$ $2-4), 53\left(n^{\circ} 1-2\right)$ y $68\left(n^{\circ} 2\right)$.

Ilippania, 1.VIII/3, núm. 200 (1998) 995-1019 
Después de 1609 se distinguirán dos tipos de cabreves: los de Segorbe y los de su «Antiguo Patrimonio». Estos últimos estarían constituidos por los bienes que formaron parte del dominio eminente señorial desde antes de 1436 y no estaban bajo control morisco cuando se procedió a su expulsión; los bienes de éstos engrosarían el patrimonio ducal con el resto de posesiones criptomusulmanas (las que antaño fueron francas o alodiales), siendo repartidas desde 1612 y declarándose desde entonces en los cabreves de Segorbe. En los cabreves del "Antiguo Patrimonio» de Segorbe, donde las instituciones eclesiásticas tenían una presencia nutrida y estaba también representada la nobleza titulada, los heterogéneos integrantes de las capas urbanas volvían a constituir un grupo significativo de censatarios. De los cabreves de Segorbe propiamente dichos debe advertirse, en primer lugar, su especificidad, de las diferencias que los distinguían del resto de cabreves analizados y que se concretaban básicamente en tres factores: que no había un censo en metálico fijo por unidad de superficie, ni siquiera para terrenos de la misma partida agraria y calidad; que la mayoría de tierras de huerta debían satisfacer un canon en especie igualmente fijo, aunque no uniforme; y que se incluian casas y tierras del término de Segorbe bajo dominios directos ajenos al duque de Medinaceli (entre sus titulares destacaban los patrones de beneficios, el convento de Vall de Cristo y, ya en el siglo XVIII, la Junta del Hospital de Segorbe).

Dada la tipología de la propiedad existente, más que una caracterización demográfica basada en los cabreves, se ha intentado cuantificar la incidencia del régimen enfitéutico entre los habitantes de Segorbe teniendo como puntos de referencia el vecindario de 1646, el padrón de 1735 y los Quinque Libri de la Catedral de Segorbe ${ }^{22}$. El resultado es que los enfiteutas vecinos representaban una proporción significativa y posiblemente en ascenso de la población, que oscilaría entre el $55 \%$ y el $70 \%$ del total. La presencia foránea, moderada en 1661 , se reveló muy importante en 1737 , alcanzando un $40 \%$ de los efectivos.

En virtud de que le era "propio el término y territorio de dicba ciudad, buerta, montes, debesas, tierras cultas e incultas, planas, montañas, prados y demás contenidos en ellasy ${ }^{23}$, $\mathrm{el}$ duque de Segorbe se benefició del incremento de terreno cultivado entre 1661 y 1737 como consecuencia de procesos colonizadores (se pasó de 10.624 a 11.844 hanegadas). En la distribución de cultivos se dio una evolución inversa entre las campas y los leñosos en beneficio de las primeras. Como para los demás señoríos, las causas deberían buscarse en las necesidades de autoconsumo, a las cuales no sería ajeno, en este caso, un entramado social complejo aunque inserto en una sociedad ruralizada y con una población en aumento. Peto era en la estructura general del dominio útil de los vasallos segorbinos en los tres cabreves coetáneos - Segorbe, su Antiguo Patrimonio y Geldo- donde se constatan las mayores diferen-

22 Seguimos para ello los datos de Camarens, J. (1966) y Agull.Ar, V. (1984).

23 A.D.M., Sección Segorbe, legajo 1, n 1-2. Toma de posesión de 1675.

24 Sobre la superficie que teóricamente cubriría las necesidades de una familia media durante el Antiguo Régimen, CASEY, J (1981), págs. $52-53$ y, más recientemente, CISCAR, E. (1993), paigs. $21-22$.

Iitpania, LVIII/3, núm. 200 (1998) 995-1019 
cias con el resto de señoríos. Aunque quizás sería arriesgado hablar de una verdadera clase de proletarios, alrededor de la mitad de los enfiteutas segorbinos reunían superficies inferiores a 8 hanegadas ${ }^{24}$, hecho que pone de manifiesto la necesidad de autoexplotación si no poseían otros bienes. La documentación complementaria existente (procedente de los libros de heredades y arrendamientos del cabildo catedralicio) no permite acotar por completo la configuración de la propiedad segorbina, pero si confirmar que sus posesiones enfitéuticas siguieron la misma modalidad de explotación que las francas o alodiales: el arrendamiento a corto plazo. En la transmisión del dominio útil, las compraventas seguían ocupando un lugar preponderante en ambos cabreves. Tanto es así que la presencia de testaferros llegó a ser un fenómeno habitual, no excepcional. Los mejores representantes de esta suerte de transacciones fueron, como en el Quinientos, mercaderes y profesionales liberales.

La sociedad segorbina que mostraban los cabreves era esencialmente agrícola, con una mayoría de titulares campesinos. Sin embargo, reflejaba una composición más compleja que las típicas comunidades rurales de la época. Quienes más descollaban entre las capas urbanas exan, numéricamente, artesanos y profesionales liberales; por su nivel de riqueza, estos últimos, ciudadanos y clérigos. Pero además, figuraban miembros de las clases privilegiadas del Antiguo Régimen: algunos representantes de la nobleza titulada y, muy especialmente, las instituciones eclesiásticas (entre ellas, determinados conventos, un cabildo catedralicio con más de 100 hanegadas de regadío en dominio útil y el Colegio de la Compañía de Jesús, con unos bienes urbanos que le convirtieron en uno de los enfiteutas más importantes del duque de Medinaceli en el País Valenciano). No es demasiado extraño que el proceso de pauperización detectado entre 1661 y 1737, afectara sobremanera a campesinos, viudas o artesanos. Frente a ellos se situaron, con dinámicas no siempre coincidentes, los restantes representantes de las capas urbanas y las instituciones eclesiásticas. En este sentido, otra diferencia de Segorbe con los señotíos que integran la presente investigación radicaría en la probabilidad de entrever, por parte de enfiteutas acomodados, estrategias familiares que se concretaron en ofrecer a sus descendientes una profesión liberal —derecho o medicina fundamentalmente- y/o adquirir la dignidad de ciudadanos. Con ello, Segorbe participaba de una de las características de la sociedad valenciana de los siglos XVII y XVIII, la movilidad social.

Una vez concluido el análisis final del señorío que presentaba una singularidad manifiesta, nos ocuparemos de las restantes baronías. En primer lugar, se impone centrar el estudio en sus parámetros más característicos. Entre los establecimientos de 1613 y el primer tercio de siglo XVIII, aparte del crecimiento de reconocimientos (descontadas las declaraciones institucionales, de 474 a 1433 vecinos), las diferencias más notorias provenían de las roturaciones que mediaron entre ambos momentos y de la inclusión de algunas regalías señoriales como dominio útil de diversos municipios. De este modo, la superficie cultivada pasó de 25.381 a 34.314 hanegadas y las cargas en metálico, de 327 a 398 libras.

I Iisputia, LVIII/3, núm. 200 (1998) 995-1019 
Con los repartos iniciales inmediatos al extrañamiento morisco se inició el proceso. Como adelantamos, la actuación de los agentes señoriales no era descrita de manera positiva por los propios repobladores. Pero para que la distribución del dominio útil no adquiriera un carácter igualitario cabria atribuir un papel esencial a la propia dinámica del proceso repoblador, que no concluyó con la firma de las cartas-puebla, sino que siguió abierto al importante flujo migratorio del momento. A la vista de la información consultada, no sería extraño que los últimos enfiteutas que fijaron su residencia en estas baronias recibieran un dominio útil menos extenso y valioso. A pesar de ello, se constituyeron unas comunidades rurales con una diferenciación interna de grado y donde la autosuficiencia de la familia campesina parecia asegurada en años de cosechas no catastróficas. Veamos cómo.

Todos los repobladores recibieron, al menos, una casa, aunque no construcciones agrarias complementarias (eras y corrales). De todos modos, la concesión de inmuebles constata diferencias notables entre los que se hubieron de contentar con una vivienda y los que recibieron más (y de buena calidad, a tenor de su censo en metálico). El reparto de la tierra fue relativamente homogéneo, asignándose a los nuevos vasallos parcelas de huerta, tierra campa y leñosos, y, además, en proporciones no excesivamente desiguales. El objetivo perseguiría cubrir las necesidades de la familia campesina con cosechas complementarias, aunque como es lógico, se vio condicionado por las potencialidades agrarias de cada lugar; en el reparto del regadío es donde se intuyó un esfuerzo señorial más decididamente equitativo. Si atendemos a las extensiones de los «lotes» repartidos, las diferencias podrían ser calificadas de notables si se consideraran en general para todos los señorios; sin embargo, tomándolas por separado para cada uno de los términos municipales, no eran excesivamente dispares. Aparte de los factores reseñados (actuación de los agentes señoriales, dilación temporal del proceso repoblador o potencialidades agrarias) habría que considerar otros como la cuantía de los nuevos censatarios y la superficie de cada municipio. La base territorial más escasa fue, sin lugar a dudas, la de Geldo; en el futuro, sus vecinos la salvaron gracias a usufructuar un dominio útil en Segorbe que llegaría a ser superior en tamaño a todo su término municipal. En cuanto al censo en metálico y con la excepción de la Vall d'Uixó, la carga media por enfiteuta se situaba entre los cánones (nnormales» - de dos a tres libras_- de los señonios valencianos repoblados a raíz de la expulsión y cuyas cartas-puebla analizó E. Císcar.

Los cabreves de 1651 revelan que la diferenciación interna de estas sociedades agrarias se acentuaba según su respectivo dinamismo. Aparte de que no todos los enfiteutas vecinos disponían ya de casa propia, la autosuficiencia familiar empezó a verse amenazada en algunos casos, haciendo acto de presencia los primeros campesinos sin tierras. Los cabreves de Geldo y la Vall d'Uixó incluían una interesante información sobre las formas de acceso al dominio útil que los de la Sierra de Eslida obviaban. Su estudio cuantitativo revela que las compraventas alcanzaban proporciones no menos significativas que las transmisiones intrafamiliates, especialmente en Geldo, donde los datos eran más completos. Como en Segorbe, el mercado del dominio útil era más dinámico 
de lo previsible en principio. El cabreve de la Vall d'Uixó recogía otro elemento diferenciador: la presencia de un grupo sumamente significativo de vasallos no campesinos, o mejor, agricultores sin una dedicación exclusiva a la tierra, los alpargateros. Esta actividad artesanal doméstica pudo convertirse en una alternativa al empobrecimiento que sufrian los enfiteutas menos afortunados a consecuencia del proceso de diferenciación interna de la sociedad campesina.

Aunque con el tiempo se agudizaron las desigualdades (de no contar con otros recursos, el empobrecimiento como propietarios útiles podía desembocar en algunos casos en auténtica pauperización), la configuración de todas y cada una de estas poblaciones como sociedades agrarias seguía vigente a finales del primer tercio del XVIII. Cierto es que los valores superficiales susceptibles de garantizar el autoabastecimiento de la familia campesina son límites siempre relativos y de difícil fijación, en cuya definición habría que comprobar con detalle, además, la calidad de la tierra declarada. Pero entre unos enfiteutas pobres sin recursos propios suficientes y los más acomodados, continuaban predominando, en 1733, unos labradores medios que controlaban una parte sustancial de la tierra cultivada en todos los señoríos que nos ocupan. Por desgracia, estos datos no se han podido complementar con otras fuentes documentales que se refirieran al terreno alodial, franco o incluso enfitéutico en señoríos colindantes ajenos a la jurisdicción del duque de Medinaceli. Tampoco es posible analizar empíricamente los sistemas de explotación que podian subyacer bajo la distribución del dominio útil definida por los cabreves; no obstante, en una zona como la estudiada, alejada de la agricultura intensiva de regadío y que no requería de grandes inversiones, no puede descartarse la utilización del arrendamiento a corto plazo.

Por otra parte, el duque de Segorbe no conseguió perpetuar uno de los objetivos perseguidos con los repartos iniciales: la racionalización productiva propia de una economía tradicional de subsistencia. Ejemplos contrastables de esta afirmación lo constituirían la evolución del parcelario y la morfología de los cultivos. La tendencia minifundista del primero se dejaba sentir particularmente donde el terreno declarado experimentó los menores avances: la Sierra de Eslida y Geldo. En la Vall d'Uixó, las importantes roturaciones efectuadas lograron mantener el tamaño de las parcelas en los niveles del Seiscientos sobre todo para el secano. En cuanto al segundo elemento señalado, eran cada vez más escasos los enfiteutas que contaban con los distintos tipos de cultivo. Pero no sólo eso; en la Vall d'Uixó, eran precisamente los que disponian de un terreno menos extenso, quienes presentaban los porcentajes más elevados de tierras de baja calidad, las campas de secano; como es lógico, esto redundaría de manera negativa en el nivel de autonomia de las familias campesinas que se encontraban en tal situación. Asimismo, debe subrayarse, como para Segorbe, el inexorable avance de las tierras campas en detrimento de los arbóreos en todas las baronías. Esta dinámica confirmaba la tendencia hacia el autoconsumo en perjuicio de productos con mayor vocación comercial, como las moreras, higueras y viña. Por su importancia en la alimentación de los animales de tiro,

Hi.punia, IVIII/3, núm. 200 (1998) 9)5-1019 
y no siendo ajeno al aprovechamiento comercial, el algarrobo experimentaba, por contra, avances generalizados.

Las estadísticas sobre el reparto de la tierra y las cargas señoriales en metálico, la parcelación o la distribución de cultivos por grupos sociales apuntan a que se estaba ante una estructura social todavía homogénea y con movilidad más bien escasa. El campesinado continuaba siendo el colectivo predominante desde cualquier perspectiva en todos los iugares. Le seguían, a mucha distancia, el grupo de viudas, mujeres y menores, que también podría considerarse, de hecho, parte integrante del campesinado en la mayoría de ocasiones. Hay que resaltar que un buen número de municipios se personaran como enfiteutas en los cabreves correspondientes. En la mayoria de ocasiones inclúan regalías señoriales (molinos, almáceras,...): la ciudad de Segorbe en el cabreve de 1651 de Geldo, el ayuntamiento de la Vall d'Uixó en 1651 y 1729 y, también para esta fecha, los de Eslida, Alcudia de Veo, Fanzara, Suera y Aín. Cuando incluían esta suerte de monopolios, el elevado censo exigido por ellos colocaba a las corporaciones locales entre los mayores enfiteutas de los respectivos cabreves. Tanto por la cuantía de los inmuebles y regalías declaradas, como por la extensión de sus predios rústicos y la forma de acceso a la mayoría de éstos (compras), destaca el dominio útil del ayuntamiento vallduixense de 1729.

La representación de las clases privilegiadas del Antiguo Régimen era mucho más reducida que en Segorbe, limitándose a las declaraciones de cinco administraciones y dos beneficios eclesiásticos en Fanzara, la Vall d'Uixó y Geldo. De cualquier modo, estos reconocimientos, junto al de distintos clérigos con patrimonios particulares suponían de facto el quebrantamiento de una de las cláusulas recogida en todas las cartas-pueblas, la que prohibía convertirse en enfiteutas a eclesiásticos y personas exentas en general.

Algunas de las categorías socio-profesionales que integraban las capas urbanas evidenciaban una creciente consolidación numética. Por tratarse de un colectivo muy heterogéneo y con unos índices de presencia y pujanza diferenciados, se impone el análisis individualizado de cada uno de ellos. Cuantitativamente, los artesanos se situaban como sus integrantes más destacados; su distribución gremial estaría encabezada por la actividad textil, seguida por la construcción y el metal. Todos procedían del seno de la comunidad rural y su dominio útil eta para muchos una fuente complementaria de ingresos. Precisamente, el referido origen permitiria explicar el disfrute de unas tenencias dispares entre unos artesanos y otros: tendría su punto de partida en el propio proceso de diferenciación interna de la sociedad campesina. Aparte de los artesanos que figuraban en los lugares de la Sierra de Eslida (en especial en Eslida y Fanzara), la dinámica más nítida de este colectivo se describió en la Vall d'Uixó, donde la polarización apuntada en 1651 cedió paso a un empobrecimiento generalizado en 1729. En estos momentos, los artesanos contaban con una extensión media y una proporción de terreno regado muy inferiores a la del conjunto. Por esta razón, caracterizarlos como agricultores pobres y sin dedicación exclusiva o a tiempo parcial se ajustaría perfectamente a la realidad.

IVispaniu, LVIII/3, núm. 200 (1998) 995-1019 
Salvo contadas excepciones, los patrimonios de religiosos a titulo particular eran ilustrativos del denominado clero bajo, aunque su terrazgo fuera, en general, más valioso que el de los artesanos. El comentario vertido a propósito del origen de los artesanos, puede aplicarse a los clérigos, ya que los más afortunados difícilmente podrían haber acumulado tales bienes contando únicamente con los ingresos de su cargo. Posesiones más extensas y valiosas reconocían los profesionales liberales; sus actividades más frecuentes eran el derecho (abogados, notarios, escribanos) y la medicina (médicos, cirujanos, apotecarios). Tanto en la Vall d'Uixó como en la Sierta de Eslida se definían como un colectivo con una base territorial consolidada y en ascenso; sus tenencias medias eran bastante extensas y sus tierras de buena calidad. No obstante, no todos estos profesionales contaban con predios rústicos y su presencia era todavia modesta. No es extraño que el número de mercaderes $y / o$ comerciantes que figuraban aquí como enfiteutas fuera extraordinariamente reducido (dos en 1651, uno en 1729) habida cuenta que su actividad se había de desarrollar en pequeñas sociedades tradicionales de subsistencia aisladas de las rutas comerciales más utilizadas; y eilo sin mencionar la importancia de las regalías y las limitaciones que la jurisdicción señorial imponía a dicho tráfico. Por su parte, los contados ciudadanos y udones» presentes se erigjan en los máximos exponentes del denominado sector inactivo o rentista. Mientras en 1651 figuraba sólo uno (Cosme Muntiel, ciudadano vallduixense), en 1729 eran tres: dos ciudadanos (Pedro López, de Fanzara; y Joseph Bonet, de la Vall d’Uixó) y un "don» (D. Pedro Gaytán, gobernador político de esta villa). Como los profesionales liberales, disponían de un dominio útil valioso, un parcelario atractivo por su extensión y unas tierras de buena calidad. Excepto el último enfiteuta mencionado, tendrían presumiblemente su origen en familias de campesinos acomodados que pudieron establecer un vínculo sobre sus posesiones. No sorprende que residieran en Fanzara y la Vall d'Uixó, dos de los núcleos de población estudiados más pujantes.

Un último apunte ha de aludir a los funcionarios señoriales. Cuando se compara a los de la Vall d'Uixó con los de las otras baronías, sorprende que aquéllos declarasen un dominio útil reducido. Y extraña, sobre todo, que esta situación fuera exclusiva de la Vall d'Uixó, donde precisamente se denunciaton los casos más notorios de excesos cometidos por procuradores de alto rango durante el proceso repoblador; y donde además, el duque recompensó los servicios prestados por los agentes que realizaron los establecimientos con tierras y casas. El hecho sólo podría explicarse si las referidas donaciones se hubieran efectuado en propiedad plena y no bajo régimen enfitéutico. Los bayles de Geldo, Eslida y Fanzara por el contrario, se situaban entre los mayores enfiteutas de los cabreves de 1651 y como labradores con un dominio útil que les permitía una autosuficiencia holgada en 1729.

En definitiva, el hecho de que las antiguas comunidades de campesinos esbozadas en 1613 experimentaran un proceso de diferenciación -variable según los casos, pero incuestionable en todos ellos-, se debió más a factores intrínsecos de su propia dinámica interna que a la actuación de grupos sociales

IIipdania, LVIII/3, núm. 200 (1998) 995-1019 
extraños a ellas. Se descubrió, es cierto, una presencia incipiente de enfiteutas ajenos al campesinado, pero su influencia era todavía escasa, su peso específico estaba, igualmente, en ciernes y ni siquiera así en algunos lugares. Sociológicamente no puede afirmarse que se diera una inversión en tierras de la llamada «burguesía agraria», selectiva y orientada a cultivos comercializables. Sirva como muestra que, en la Sierra de Eslida, los enfiteutas menos afortunados solían mantener unos porcentajes elevados de regadío; o que, de manera generalizada, se advirtió una tendencia hacia el autoconsumo, tal y como revela la evolución de los cultivos. Dado que nos encontramos ante unas poblaciones alejadas de los grandes núcleos productores y comercializadores, asi como que ni hubo un igualitarismo en los repartos de 1613 ni se dio una dedicación del terrazgo a cultivos comerciales de elevada rentabilidad que atrajeran inversiones de la burguesía urbana, posiblemente se diera aquí un proceso paralelo al que J. Millán describe para otras zonas y que se refiere a que la concentración del dominio útil originó la aparición de «una sèrie d'oligarquies d'origen camperols 25 . Donde habría que incluir una salvedad sería, como es obvio, en relación al término uoligarquía».

Tampoco se dio una acumulación de tierras por parte de la nobleza titular. De hecho, en ningún momento aparece referencia alguna a pertenencias señoriales de tipo agropecuario, salvo en los cabreves segorbinos, y siempre de muy escasa entidad. Pero es más, casi podría decirse que el duque de Medjnaceli inició su ocaso en pleno siglo XVIII, si no enajenando, sí permitiendo la titularidad de algunas regalías básicas para el control de la propiedad y la producción agrarias a favor de determinados municipios, a los cuales les fueron establecidas en calidad de dominio útil. Con las redenciones de censos enfitéuticos del siglo XIX perdería de este modo, no sólo la base territorial en estos señoríos, sino también otros bienes que había conservado en pleno dominio desde los repartos de 1613.

\section{COMPOSICIÓN Y EVOLUCIÓN DE LA RENTA DUCAL}

En este último capítulo se analiza la composición y tendencia de la renta ducal, exponente de un régimen señorial remodelado en 1609 y de la autoridad feudal sobre las distintas baronías. Resulta inexcusable insistir en que las limitaciones de la documentación consultada han imposibilitado obtener índices generales evolutivos, determinar fases de expansión o retroceso o valorar el desarrollo preciso

25 MiLLÁN, J. (1986), págs. 115-116.

26 ARDit, M. (1993), II pág. 140.

27 Los datos para el estudio de la renta proceden en su totalidad del A.D.M. Los anteriores a la expulsión, de la Sección Segorbe, legajos 61 (doc. $n^{\circ} 9,19$ y 58) y 62 (doc. $n^{\circ} 2,12$ ). Los posteriores, de la Sección Segorbe, legajos $6\left(n^{\circ} 28\right), 7\left(n^{\circ} 1\right), 8\left(n^{\circ} 44-c\right), 13\left(n^{\circ} 6-8\right), 14\left(n^{\circ} 17\right.$ y 25$)$, y $124\left(n^{\circ}\right.$ $2949,2950$ y 2971$)$; y de la Sección Archivo Histótico, legajos $57 .\left(\mathrm{n}^{\circ} 1-2\right)$ y $197\left(\mathrm{n}^{\circ} 1\right)$. Se trata de información heterogénea que incluye contadurias generales de los diferentes estados valencianos, relaciones de bienes, arrendamientos, ... 
de lo que M. Ardit designa como «empresa señoriab» ${ }^{26}$, para lo cual se precisaría, además, su contabilidad integra. A pesar de todo, creemos que este capítulo puede contribuir al avance del conocimiento de la renta señorial en el País Valenciano, aportando nueva información al respecto y confirmando, o en su caso matizando, conclusiones obtenidas por estudios anteriores ${ }^{27}$.

Las rentas del duque de Segorbe no diferían de las de otras grandes casas nobiliatias valencianas. Estaban compuestas por: a) Derechos jurisdiccionales o rentas procedentes del ejercicio directo de la jurisdicción. b) Tercio diezmo. De acuerdo con el «Resumen de rentas, regalias, propios y demás derechos del duques ${ }^{28}$, en Segorbe representaba la cuarta parte del diezmo y primicia de todos los frutos del término; en Benaguasil se pagaba décima también sobre todos los frutos, siendo de $1 / 10$ para el trigo y $1 / 12$ para el arroz. Las testantes poblaciones no pagaban diezmo en especie sino en dinero, con un montante de 70 libras anuales. c) Censos enfitéuticos, que ya hemos expuesto. d) Monopolios o derechos probibitivos y privativos, también conceptuados como «regalías». Destacaban los referidos al término y territorio, hierbas, montes, etc., que convertían al señor en su único dueño; y, especialmente, los centros productivos - molinos, hornos, almáceras, ...-y de intercambio comercial — tiendas, tabernas, etc. e) Casas y fincas señoriales. El patrimonio ducal en propiedad plena era muy reducido, limitándose a algunas casas y contados huertos o «jardines» de corta extensión: «jornaly medio» en Segorbe; «dos fanegas» en Geldo y «dos cabizadas» en la Vall d'Uixó ${ }^{29}$. f) Finalmente, los réditos por préstamos dinerarios realizados por los señores. Los incluimos como una componente más de la renta señorial por cuanto constituye una partida que puede ser relevante para conocer su dinámica global.

Se comprueba así la importancia de los derechos dominicales; su arrendamiento al mejor licitador los convertía en la principal fuente de la renta. Pero aunque es cierto que en ellos aparecían indisolublemente unidos el derecho de propiedad y la autoridad política, no lo es menos que la documentación distingue perfectamente su contenido y origen. Sirva como ejemplo lo que se indica a propósito de los exigidos en Segorbe, donde dichos derechos se abonaban en concepto de ulas casas y heredades que se poseen de los moriscos y del Antiguo Patrimonio, $y$ derechos de luismos». En consecuencia, y aunque en algunos señorios se englobara la percepción del tercio diezmo, la cuantía de éste - siempre inferior a la partición de frutos- no debe variat la interpretación de que provenían, básicamente, de derechos de propiedad (en este caso, del dominio directo) sobre casas y tierras. Derechos de propiedad que quedaron sucesivamente confirmados con las cabrevaciones analizadas.

Como se preveía, el duque de Segorbe no contaba con una propiedad consolidada importante, sino únicamente con pequeños huertos cuya incidencia

28 A.D.M. Sección Archivo Histórico. Legajo 57, $\mathrm{n}^{\circ}$ 64. Documento del siglo XVIII.

29 A.D.M. Sección Archivo Histórico, legajo $201, \mathrm{n}^{\circ} 5$. "Relaciones formadas de orden de su Excelencia de todas las alajas, propiedades y rentas que pertenecieron y deven pentenecer a la Casay.

Heipania, LVIII/3, núm. 200 (1998) 995-1019 
era mínima en el montante total de la renta. Esta debilidad de la propiedad territorial plena tenía su contrapunto en la notable participación de dos partidas de marcado carácter político o jurisdiccional: el tercio-diezmo y los monopolios o derechos prohibitivos y exclusivos. Salvo en los lugares de la Sierra de Esiida y la Vall d'Uixó, donde consistía en una cantidad fija en metálico, el tercio-diezmo podía representar proporciones considerables en la estructura de la renta ducal. En Segorbe, constituía un 15\% en el sexenio 1658-1663; en Benaguasil no se ha podido calcular dicho nivel por recaudarse conjuntamente con la partición alícuota de frutos; pero donde mayor incidencia alcanzaba, incrementándose además hasta el $64 \%$ en 1757-58, era precisamente en la Pobla de Vallbona, baronía donde mayores dificuitades encontró la renta señorial para adaptarse al alza de precios. De lo que no cabe duda es de la capacidad de adecuación a las coyunturas inflacionistas de unos ingresos impuestos directamente y de manera «universal» sobre la cosecha (el tercio diezmo) o que gravaban las actividades de los centros productivos y de intercambio comercial (monopolios). Dicha capacidad se traduciría en un incremento de su nivel de representatividad dentro de la evolución temporal de la renta ducal, especialmente frente a las cargas en metálico enfitéuticas. De todos modos, tampoco debe olvidarse que antes del extrañamiento morisco los dos conceptos en cuestión alcanzaron unos niveles de representatividad aún mayores: en los arrendamientos de 1572.74 alrededor del $87 \%$ en Segorbe y del $99 \%$ en la Vall d'Uixó y la Sierra de Eslida (en este último caso se incluían los restantes tributos de corte político, impuestos fijos y tasas comunales).

Todo parece indicar que los distintos señotíos del ducado de Segorbe consiguieron adaptarse positivamente a la tendencia inflacionista que marcaban los precios del trigo. Dicha adecuación no fue uniforme para todo el estado debido al diferente grado de reorganización que experimentó el régimen señorial con la expulsión de los moriscos en las diversas baronías que conformaban el ducado. En general, y con la excepción de la Pobla de Vallbona (que, como vimos, quedó totalmente al margen del proceso), las particiones de frutos fueron un elemento clave en la citada adaptación, junto a los derechos prohibitivos y exclusivos propiedad del señor y, en algunos casos (Segorbe, Geldo, Benaguasil y Paterna) tercio diezmo en especie. Sin embargo, la explicación no reside en exclusiva en la dinámica originada a raíz del extrañamiento criptomusulmán. La caracterización del régimen señorial con anterioridad a 1609 y su correspondiente nivel de detracción siguió constituyendo un factor decisivo en la evolución de la renta alli donde la repoblación no fue necesaria (Paterna y la Pobla de Vallbona) o completa (Segorbe).

De esta variada gama de casos que abarcaba la estructura de la renta, en uno de los extremos se situarían los señoríos que, habitados exclusivamente por cristianos viejos, no experimentaron una remodelación del régimen señorial. El ejemplo más claro era la Pobla de Vallbona, donde sólo el tercio diezmo evitaba el estancamiento de la renta señorial (el ingreso esencial de antaño, la pecha, quedó plenamente devaluado en el siglo XVIII). Muy diferente sería el caso de los señotíos de moriscos, cuyo proceso tepoblador posibilitó la reor- 
denación del régimen señorial. El mejor representante de este otro polo sería Benaguasil, localidad limítrofe con la Pobla de Vallbona. Aparte de haberse asegurado importantes sumas en metálico en un primer momento, el hecho de contar con imposiciones ajustables a procesos inflacionarios (partición de frutos, tercio diezmo y derechos monopolísticos) explicaría una evolución de la renta señorial más que destacada. Entre ambos extremos se situarían la Vall d'Uixó y los lugares de la Sierra de Eslida, que no satisfacían su parte de diezmo en especie sino en una reducida cantidad fija en metálico. También aquí cabria ubicar a Segorbe: pese a no contar ya con el impuesto de la pecha y haber establecido los monopolios más valiosos a la propia ciudad, las restantes regalías, junto al tercio diezmo y los censos enfitéuticos, particularmente los establecidos en especie, permitían un relativo margen de actualización de los ingresos.

Las cifras son elocuentes al respecto. El montante de la renta ducal pasó en Segorbe de 2.811 libras en 1574 a 4.122 en 1661 y a 4.643 en 1763 . En Benaguasil (y la Pobla deValibona, porque la documentación los toma conjuntamente), de 6.350 libras en 1608 a 3.981 en 1661 y 8.562 en $1763^{30}$. En la Vall d'Uixó y las poblaciones de la Sierra de Eslida, de 3.707 libras en 1601 a 4.492 en 1661 y 10.255 en 1763. Se comprueba así una evolución general de la renta más positiva que la existente hasta 1609 en estos señoríos, pero también que la registrada en otros grandes estados señoriales valencianos durante el mismo período. Merced a la imposición de un nuevo sistema de detracción, no sólo se consiguió con relativa celeridad una recuperación del montante bruto de la renta anterior, sino que la situación financiera de la Casa llegó a ser lo suficientemente saneada como para redimir progresivamente su deuda censal. Una prueba significativa de la evolución descrita residiría en el crecimiento que experimentó la renta señotial en relación al avance de los precios del trigo. Entre 1661 y 1763 , frente a un incremento del $137 \%$ de este cereal, el del conjunto del ducado fue del $166^{\prime} 5 \%$ (por dominios señoriales, el de Benaguasil-La Pobla fue del $215 \%$; el de Segorbe, del $116 \%$; y el de la Vall d'Uixó-Sierra de Eslida, del $228 \%$ ).

\section{RECAPITULACIÓN FINAI.}

Pese a sus innegables efectos negativos, la expulsión de los moriscos en los señotios valencianos de la Casa de Medinaceli, no tuvo las catastróficas consecuencias sobre la economía y sociedad documentadas para otros estados valencianos. Se ha comprobado que su recuperación demográfica seguiría de cerca las pautas del conjunto del País Valenciano, superándose los efectivos anteriores a 1609 en el primer tercio del siglo XVIII. Pero no sólo eso, la repoblación impulsó el proceso de concentración de la propiedad de la tierra y

\footnotetext{
30 Para 1757-58, aparece desglosada su procedendia: 7.889 libras son de Benaguasil y 1.097 de la Pobla.
}

HJipania, LVIII/3, núm. 200 (1998) 995-1019 
supuso una reorganización del régimen señorial que le permitió adecuarse mejor a los futuros movimientos inflacionistas. La evolución de la renta feudal en relación a los precios del trigo ratifica este planteamiento. Igualmente ha sido puesto de manifiesto que la citada reestructuración no llevó implícito un fenómeno de refeudalización, conclusión a la que se ha llegado tras contrastar las condiciones explicitadas en las cartas-puebla con las existentes con anterioridad en los propios señorios y cotejándolas con documentación que informaba acerca de sus modificaciones ulteriores ("concordias»).

El reparto de los bienes que habian pertenecido a los moriscos se realizó mediante el sistema de establecimientos enfitéuticos, el cual se convirtió desde entonces en el único existente para la mayoría de señoríos. Las excepciones fueton protagonizadas por los municipios donde los cristianos viejos habian constituido el elemento esencial de la población: Segorbe, la Pobla de Vallbona y Paterna. En consecuencia, y habida cuenta que el análisis del reparto y evolución del dominio útil se ha centrado en el ducado de Segorbe, únicamente la ciudad del mismo nombre escaparía a una caracterización global de su estructura de la propiedad basada en las cabrevaciones sucesivas. Con el estudio diacrónico y sincrónico de los cabreves se comprobó que las comunidades rurales originadas a partir de los repartos de 1610-1613, si no igualitarias sí bastante homogéneas, vieron incrementarse paulatinamente su diferenciación interna. Aun así, y al menos hasta el primer tercio del siglo XVIII, seguían constituyendo ejemplos típicos de sociedades agrarias con un escasísimo grado de movilidad social. Este hecho no impide resaltar, en los casos donde la documentación lo permitia, que el mercado de la tierra - e incluso el de bienes inmuebles - fuera bastante dinámico, destacando la presencia de compra-ventas en la transmisión del domirio útil.

Por grupos sociales, la participación del campesinado y su grupo afín, conformado por viudas, mujeres y menores, condicionaron las distintas estadísticas confeccionadas. Sólo en Segorbe y, en parte, la Vall d'Uixó, se obtendrian resultados un tanto divergentes. Pero incluso Segorbe, que contaba con una presencia relativamente significativa de enfiteutas enmarcados entre las «capas urbanas", aparecía como una sociedad claramente ruralizada. En ningún caso puede afirmarse que se diera una clara inversión en tierras por parte de la denominada burguesía agraria orientada a productos comercializables de regadío.

\section{Nota sobre equivalencias y abreviaturas:}

1 hanegada $=1 / 12$ hectárea

1 libra $=12$ sueldos; 1 sueldo $=20$ dineros

\section{BIBLIOGRAFIA}

AGULAR MORELLA, V., (1984) «Demografia histórico-sanitaria de la ciudad de Segorbe. (17291870)", Centro de Estudios del Alto Palancia, núm. 3, 1984.

Hijpaniu, LVIII/3, núm. 200 (1998) 995-1019 
ANDRÉS ROBRES, F, Crédito y propiedad de la tierra en el Pais Valenciano (1600-1810), València, Institució Valenciana d'Estudis i Investigació, 1987.

ARDIr, M., Els bomes $i$ la terra del Pais Valencià (segles XVI-XVIII), 2 tomos, Barcelona, Biblioteca d'Histònia dels Paisos Catalans, Curial, 1993.

ARDIT, M., «Expulsió dels moriscos i creixement agrari al País Valencià», Afers, 5/6, 1987, pp. 273-316.

Arroyo Ilera, F., El alto y medio Palancia, Castelló, Ajuntament de Castelló, 1981.

ATIENZA HERNÁNDEZ, I, Aristocracia, poder y riqueza en la España moderna. La Casa de Osuna, siglos XV-XIX, Madrid, Siglo XXI de Editores, 1987.

BARCEIÓ TORRES, M. C., «L'Allfondeguilla y Castro. La siłuación de los mudéjares castellonenses en el siglo XIII), Boletín de la Sociedad Castellonense de Cultura, núm. 50, 1974, pp. 126-139.

BENIITEZ SÁNCHEZ-BLANCO, R., "Formas de transmisión de la propiedad en el Pais Valenciano (siglos XVII y XVIII). Aptoximación metodológica a un nuevo tratamiento de una fuente notarial clásica: los cabreves», La documentatión notarial y la bistoria, I, Santiago, Universidad de Santiago de Compostela, 1984, pp. 353-370.

BORONAT y BARRACHINA, P., Los moriscos españoles y su expulsión. Estudio bistórico-critico, 2 volúmenes, València, Francisco Vives Mota, 1901.

BURNS, ROBERT I., «Els mudèjars valencians del Regne de València de la generació posterior a la croadas, Història del País Valencià, tomo II, Barcelona, Edicions 62, 1989.

BUTZER, K.W. y otros, «Una alqueria islámica medieval de la Sierra de Espadán», Boletin de la Sociedad Castellontense de Cultura, LXI, 1985, pp. 305-365.

CAMARENA MAHIQUES, j, Padrón demográfico-económico del reino de Valencia, 21735 ?, València, Universitat de València, 1966.

CÁRCEL ORTí, Ma M., Relaciones sabre el estado de las diócesis valencianas, tomo I, València, Generalitat Valenciana, 1989.

CARMINAL, M.; CANALES, E.; SOLÀ, A. y TORRAS, J., «Movimiento del ingreso señorial en Cataluña (1770-1835). Los arriendos de la Casa de Medinacelis, Historia agraria de la España Contemporínea, tomo I, Barcelona, Crítica, 1985, pp. 433-453.

CASEY, J, «La situación económica de la nobleza valenciana en visperas de la expulsión de los moriscosn, Homenaje al Dr. Juan Reglá Campistol, tomo I, València, Universitat de València, 1975, pp. 515-527.

CASEY, J., El Regne de Valencia al segle XVII, Barcelona, Curial, 1981.

CAVANILJ.ES, A. J., Observaciones sobre la bistoria natural, geografia, agricultura, poblacion y frutos del Reyno de Valencia, dos tomos, Madrid, 1795-1797, (València, 1989).

CISCAR PALJARÉs, E., Tierra y señorio en el Pais Valeniano. (1570-1620), València, Del Cenia al Segura, 1977.

CISCAR PALLARÉs, E., Moriscos, nobles y repobladores, Alfons el Magnànim, València, 1993.

DOMíNGUEZ, A. I VINCENT, B., Historia de los moriscos. Vida y tragedia de una minoria, Madrid, Biblioteca de la Revista de Occidente, 1978.

ESCOLANO, G., Década primera de la bistoria de la insigne y coronada ciudad y Reyno de Valencia, València, Universitat de València, Departament d'Histònia Moderna, 1610-1972.

FELIU I MONIPORT, G., «L'estudi serial dels capbreus com a font per a la història agrària. L'exemple del palau d'Anglesolas, Primer colloqui d'bistòtia agrària, Barcelona, I.A.M, 1978, pp. 213-228.

FRADEJAS, C. y GARCIA, P., «El régimen señorial en Segorbe: 25 heredades de moriscos, en la partida «del Censab bajo señoria directa de la cartuja de Valdecristo. 1483-1627», Centre d'Estudis municipals d'Onda, núm. 3, Onda, 1990.

GarcíA, H, "Orígenes del Ducado de Segorbe», Boletín de la Sociedad Castellonense de Cultura, núm. XIV, 1933 , pp. 466-489.

GIL OJCINA, A. La propiedad señorial en tierras valencianas, València, Del Cenia al Segura, 1979.

Gual CAMARENA, M., Las cartas pueblas del Reino de Valencia, València, Generalitat Valenciana, 1989.

GUICHARD, P., «El impacto de la reconquista en la sociedad musulmana», Historia del pueblo valenciano, tomo I, València, Levante, 1988.

Hìpania, LVIII/3, nưm. 200 (1998) 995-1019 
GuINOT, E., Cartes de poblament medievals valencianes, València, Servei de Publicacions de la Presidència, Generalitat Valenciana, 1991.

GUINOT, E., «El Patrimoni Reial al País Valencià a inicis del segle XV», Barcelona, Anuario de estudios medievales, volumen XXII, 1992, pp. 581-639.

GƯTIÉRREZ BERNAL, J., «Sintesis de distribución y produccciones agropecuatias en Segorbe y poblaciones circunvecinas", Biblioteca de Estudios de Segorbe y su Comarca, núm. 13.

HALPERIN DONGiHI, T., Un conficto nacional. Moniscos y cristianos viejos en Valencia. València, Alfons el Magnànim, 1980.

HAMILTON, E. J., El tesoro americano y la revolución de los precios en España, 1501-1650, Barcelona, Ariel, 1975.

LAPEYRE, H, Geografia de la España morisca, València, Diputació de València, 1986.

LLORENS Y RAGA, P. L., «La morería de Segorbe. Las rentas de su mezquita a fines del siglo XVIn, Boletin de la Sociedad Castellonense de Cultura, núm. XIIX, 1973, p. 303-324.

LJORENS Y RAGA, P.L., cLos sartacenos de la Sierra de Eslida y la Vall d'Uxó a fines del Siglo XV', Boletin de la Sociedad Castellonense de Cultura, núm. 43, 1967, pp. 53-67.

MARnVALL, J.A. «Trabajo y exclusión: el trabajador manual en el sistema social español de la primera modernidad", Les problemer de l'extiusion en Espagne (XVT - XVIT' siècles). Idéologie et discours, Sorbonne, Publications de la Sorbonne, 1983, pp. 135-159.

NiCOLAU I BAUZA, J., Pagines de la bistòria de Benaguasi, Benaguasil, Ajuntament de Benaguasil, 1990.

PALOP RAMOS, J. M. y BENÍTEZ SÁNCIEZZ BLANCO, R., «Evolución de la renta feudal valenciana en el siglo XVIII", Prestations paysannes, dimes, rente foncière et mouvement de la production agricole a l'èpoque préindustrielle, tomo I, Paris-La Haya, 1982, pp. 417-430.

PENARROJA TORREJON, L., Moriscos y repobladores en el Reino de Valencia: La Vall d'Uxó (15251625), dos volumenes, València, Del Cenia al Segura, 1984.

PÉREZ GARCIA y ARDIT, M., «Bases del crecimiento de la población valenciana en la Edad Modernas, Estudis sobre la població del País Valencià, I, València, IVEI, 1988, pp. 199-228.

PESET, M; MANCEBO, M; y GRAULLERA, V., «Plets, senyories i propietat a la València del segle XVIII", Estudis d'Historia Agrària, núm. 6, Barcelona, Curial, 1987, pp. 203-239.

PESET REIG, M., «L'emfiteusi al Regne de València. Una anàliși jutídica», Estudis d'Història Agrària, núm. 7, Barcelona, Curial, 1989, pp. 99-126.

PESET RETG, M., Dos ensayos sobre la bistoria de la propiedad de la tierra, Madrid, EDERSA, 1988.

PESET, M. y GRAULLERA, V., «Nobleza y señorios en Valencia durante el siglo XVIII», Estudios de Histonia Social, núm. 12-13, Madrid, 1980. pp. 245- 281.

REGLA், J., Estudios sobre los moriscos, València, Universitat de València, 1971.

ROMERO GONZÁLEZ, J., «Les estructures de propietat de la terra i de les unitats d'explotació al País Valencià. Mètode i fonts per al seu estudin, Economia agrària $i$ història local,València, Institució Alfons el Magnànim, 1981, pp. 161-183.

SABORI'r BADENES, P., Morir en el Alto Palancia. La religiosidad popular a través de los testamentos. Siglos XVT-XVTIJ), Segorbe, Maria de Luna, Ayuntamiento de Segorbe, 1991.

SANCHEZ GONZÁLEZ, A., «Señoríos y jurisdicciones de la Casa de Medinaceli durante el siglo XVIII en el Reino de Valencias, ponencia del Congreso de Historia celebrado en Segorbe, 1991.

TORRES MORERA, J. P., Repablación del Reino de Valencia después de la expulsión de las moriscas, València, Ajuntament de València, 1969. 